\title{
PHOTOGRAPHING INCLUSIONS
}

By John I. Koivula

Although the general principles of photomicrography are easily learned and applied, high-quality photomicrography is an art that is mastered only with time and great patience. The microscope must be kept scrupulously clean, and the effects of light on the subject inclusion must be fully understood in order to determine what method(s) of illumination will yield the most useful photographic image. Specialized techniques that can save film and time, while producing top-quality photomicrographs, are usually learned only through long hours of experience. This article discusses some of these techniques, such as the importance of a properly prepared microscope and photographic subject, as well as the control of vibrations and exposure time. In addition, the various methods of illumination that are adaptable to a standard binocular gemological microscope are introduced.

\section{ABOUT THE AUTHOR}

Mr. Koivula is the senior staff gemologist in the Gem Identification Department of the Gem Trade Laboratory, Inc., Santa Monica, CA.

Acknowledgments: The author wishes to thank Tino Hammid, of the Gem Media Department of $G / A$, for the two fine black-and-white equipment photographs; and Peter Johnston, also of Gem Media, for the four excellent line drawings which illustrate the various lighting techniques.

1981 Gemological Institute of America
D hotomicrography of inclusions in gems requires the combined techniques of gemological microscopy, photomicrography, and the various specialized methods of illumination that aid in capturing images of a gem's interior on film. It is a simple matter to load film and place a camera body with a microscope adapter over a microscope eye piece, put a gem in the microscope's gem holder, focus on the inclusions within, and start snapping pictures one after the other by pushing the button on the cable release. These, however, are only the first small steps toward good photomicrography.

A sound working knowledge of inclusions in gems and how they react to various forms of illumination is vitally important. This knowledge is the first major step toward outstanding photomicrography. Along this road of learning there are a number of stumbling blocks. How should exposure time be controlled? What about long exposures? How can vibration be reduced? What illumination techniques are available and how can they best be used? And so on.

It is my intent in this article to introduce some important considerations for photographing inclusions through a microscope and to help remove many of these stumbling blocks for the interested gemologist. This article does not attempt to reiterate the "how to" of photomicrography, which has been presented in numerous other articles (some excellent references, for example, are Gander, 1969; Lawson, 1960; Loveland, 1970; Webster, 1966; and Eastman Kodak Co., 1974). Rather, it reports the specific application of these techniques to, and in many cases their refinement for, photographing inclusions.

\section{WHY PHOTOMICROGRAPHY?}

Not only are inclusion photographs often quite beautiful, but they can be highly informative as well. Properly identified and catalogued, photomicrographs can serve as a visual reference library that greatly aids the gemologist both in the routine identification of gemstones and in the 
determination of their origins, especially whether natural or synthetic. It is neither economical nor feasible for one individual to own every gem with interesting inclusions that has ever been encountered, and it is impossible to remember the internal characteristics of every major gem species. With photomicrographs, however, important inclusion characteristics are always available for quick reference.

Photomicrography also affords the jewelergemologist a permanent record of the internal characteristics of a specific gemstone. Inasmuch as no two inclusion images are ever exactly alike, the jeweler-gemologist, aided by photomicrographs, can identify beyond reasonable doubt a specific previously photographed stone. Even if a gem is recut, as long as the inclusions are deep within the stone rather than right on the surface, the stone can be identified through previous photomicrographs.

\section{GETTING A CLEAN START}

A good microscope should be treated as you would treat any precision instrument. When not in use, it should always be covered. Never smoke around optical equipment, and avoid eating while taking photomicrographs. Although these precautions should slow the process, oculars, objectives, and phototube lenses will eventually become dirty. Accordingly, when lens cleaning is needed, a can of compressed air should be used first to blow off all loose dirt particles. Then a soft camel's hair brush can be employed to lightly loosen any stubborn dust so that another dose of compressed air will blow it away. Oily or greasy smudges can be cleaned with either distilled water /easily produced by breathing on the lens surface) or any of the standard quick-evaporating lens cleaners and a lint-free lens tissue. Never dry-wipe a lens, as this will damage the coating and almost always guarantees a scratched surface. Dirty lenses produce fuzzy, blurred photomicrographs, making it virtually impossible to obtain a critical focus on the subject.

A clean photographic subject is almost as important as clean lenses on the microscope. Tiny dust particles appear as bright hot spots on the developed film, and oily smudges and fingerprints will distort the view of the gem's inclusions. If the subject is very oily, a standard lens cleaner and lens tissue can be used to clean the surface. Normally, though, just wiping the stone off with a clean, lint-free gem cloth is sufficient. Canned air, a blower brush, and a fine-point needle probe can be used to remove small dust particles that are attracted to the surface after the initial cleaning. A useful collection of items for the routine cleaning of microscope lenses and subjects, as shown in figure 1 , should be kept close at hand.

Pyroelectric species such as tourmaline are often troublesome dust gatherers when they are slightly warmed by the microscope illuminators commonly used. Therefore, a cool, fiber-optic light source is recommended for the illumination of such materials.

\section{THE TIME FACTOR}

Many gemologists rush their preparation for a photomicrograph, and a poor end product almost invariably results. The beginner in a hurry will end up with a far higher incidence of failure than of success. Speed will come only with experience. Whenever possible, as much time as is necessary should be invested to clean the subject thoroughly and adjust the lighting to adequately illuminate the desired features. A few extra moments taken in the initial set up will not only save film, but will also eliminate the necessity of a reshoot in most cases. It should be remembered that the number of mistakes made increases as the time spent decreases, so if you want good inclusion photomicrographs, be prepared to spend the time.

Figure 1. A collection of items useful in cleaning microscope and gem alike. These are, from left to right: lens paper, lint-free gem cloth, lens cleaner (two brands displayed here), needle probe, small camel's hair brush, can of compressed air, and camel's hair blower brush.

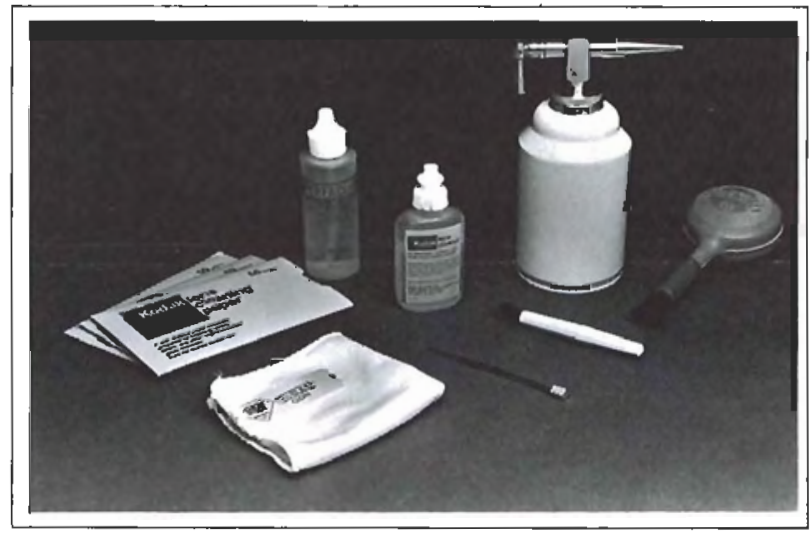




\section{CONTROLLING VIBRATIONS}

Common vibration is often responsible for many a ruined photomicrograph. As exposure time and magnification increase, vibration problems also increase. The problem is how to isolate the photomicrographic unit from unavoidable room vibrations during the entire exposure cycle. Optical isolation benches and air flotation tables have been designed for this specific purpose, but their costs are prohibitive for most photomicrographers. Making your own vibration control stage is the logical alternative, and this is easily done.

Start with a hard, thick-surfaced, sturdy table as a primary base. Place a rubber cushion / such as a typewriter pad) on the table. Then put a $1 / 4$ - to $1 / 2$-inch-thick steel plate on the rubber cushion. Next, position another rubber cushion over the steel plate. On this cushion, place a l- to 3 -inchthick granite (or similar rock) slab. Flat, preshaped, and finished rock slabs can be obtained from a local stone mason. The photomicrographic unit will rest on the rock slab. The rubber cushions effectively eliminate short, sharp vibrations while the table top, steel plate, and rock slab reduce rolling vibrations of longer wavelengths. This method eliminates vibrations for virtually all magnifications less than about $150 \times$.

Even when an anti-vibration base is used, care must be taken to avoid touching the microscope itself, the table, or any miscellaneous equipment on the table during the actual exposure.

\section{EXPOSURE TIME}

Long exposure times are one of the inclusion photomicrographer's worst enemies because of the potential for color shifts in the film and vibration problems. The speed of the film used and the amount of light reaching the film dictate the length of exposure. In attempting to reduce exposure time, usually it is better to apply additional light to the subject than to use a faster film. In general, the higher the film speed is, the greater the graininess of the film will be. If the recorded image is to be enlarged, this should be considered. Also, as the film speed increases, the quality of the colors obtained decreases. There is an obvious difference in color saturation and richness between photographs taken with 50 ASA film and those taken with high-speed 400 ASA film.

\section{ILLUMINATION TECHNIQUES}

Dark-field Illumination. Through the microscope, the routine observation and photography of inclusions in gem materials is greatly aided by the use of dark-field illumination. In the darkfield technique, the direct transmission of light
Figure 2. In dark-field illumination, the direct transmission of light from below the stone is blocked so that only indirect side light reflected from below reaches the subject.

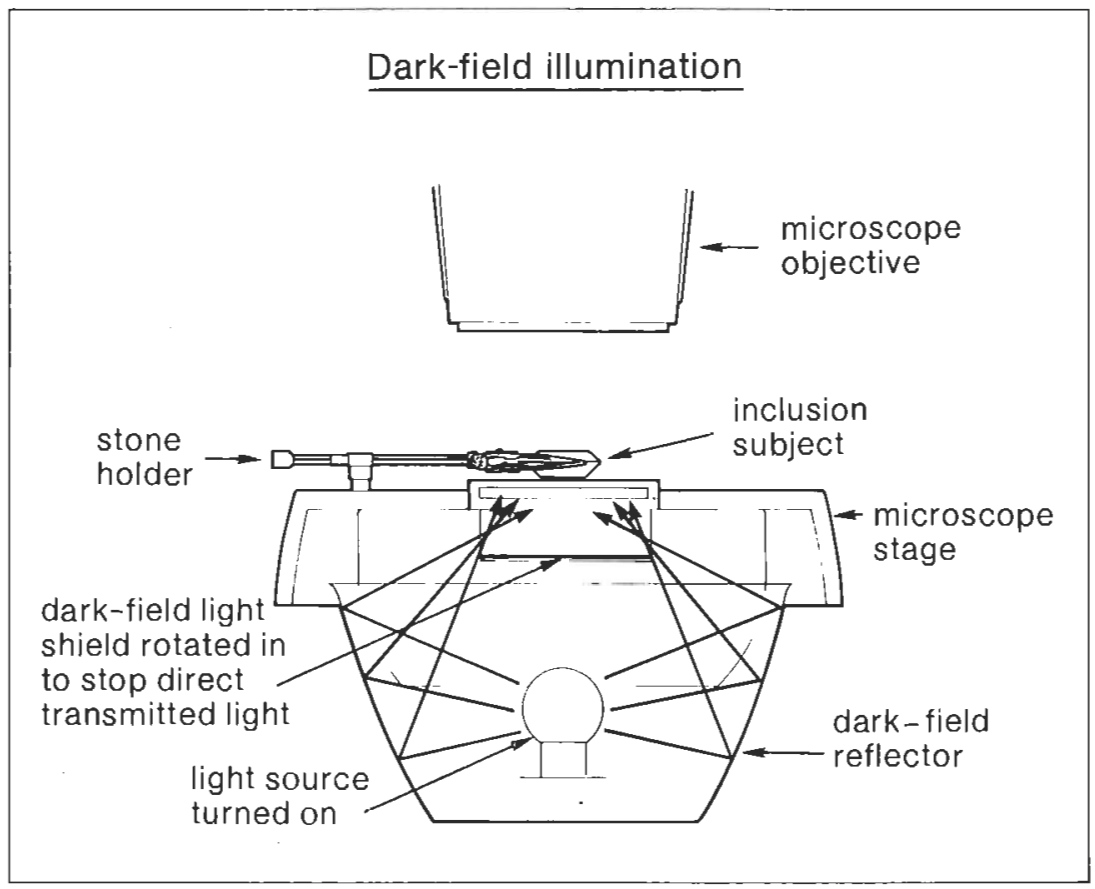




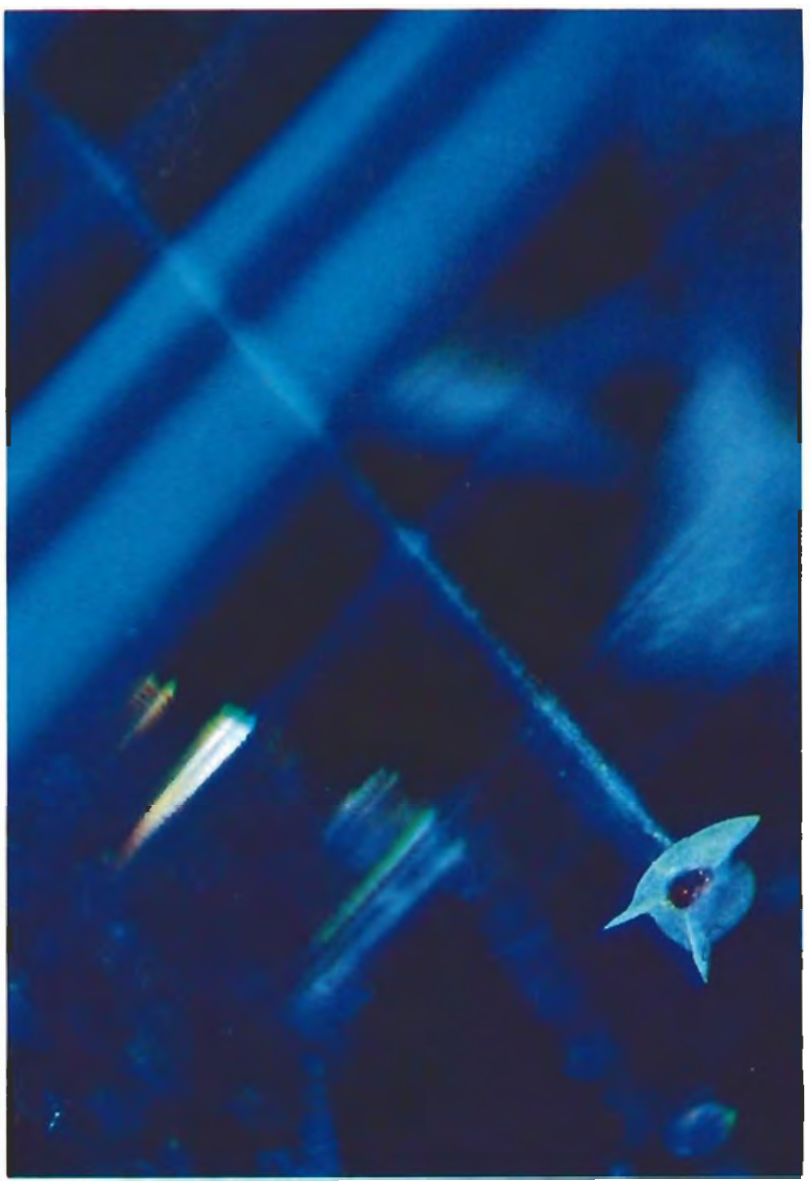

Figure 3. Reminiscent of the Pailin, Cambodia, urano-pyrochlors, these two tiny, intergrown, orange-red garnets, surrounded by a residual liquid halo, seem to streak through their Thai sapphire host. The "comet tail" is the result of directional growth disturbance caused by the garnets. Dark-field illumination, magnified $45 \times$.

from below through the inclusion host is blocked by a dark-colored (preferably black), opaque lightshield. The only light to reach the subject is indirect side light reflected from below around the sides of the opaque light shield by a hemispherical or circular mirror-like reflector (figure 2).

With this technique, only light that is scattered or reflected by the inclusions enters the microscope objectives and passes to the film plane. The inclusion subjects are seen very brightly against a dark background. Even tiny inclusions stand out in high relief, and a tremendous amount of detail may be photographed. Dark-field lighting is most applicable to the study of included crystals (figures 3 and 4), some small fluid inclusions, healing fractures (figure 5), and cleavages.

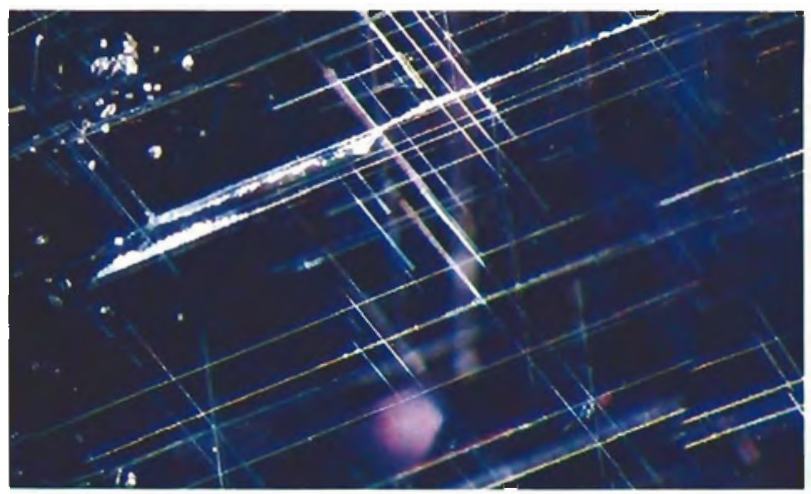

Figure 4. Often mistaken for rutile, this latticework of boehmite, $\mathrm{AlO}(\mathrm{OH})$, in an African sapphire is the result of stress along repeated twin junctions. Dark-field illumination, magnified $60 \times$.

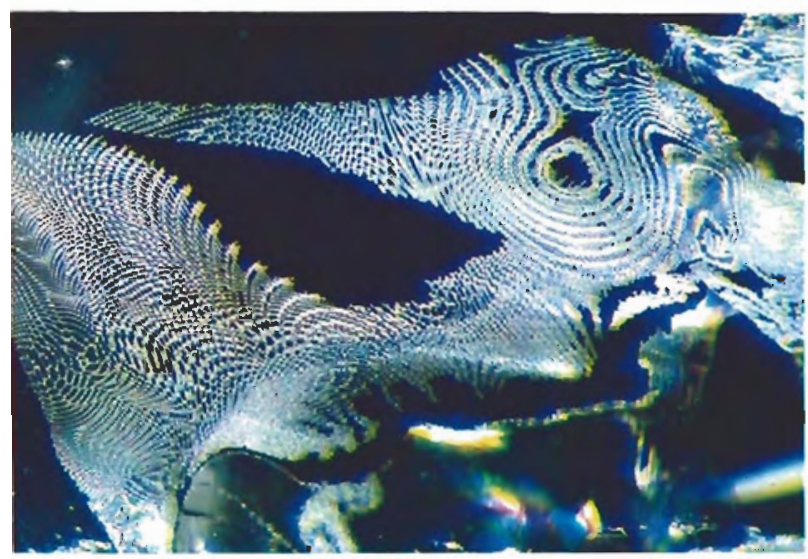

Figure 5. The descriptive term fingerprint readily applies to partially healed fractures such as this one in rock crystal quartz from Brazil. Dark-field illumination, magnified $50 \times$.

For dark-field photomicrography, the subject must be very clean, since dust on the surface of the host readily stands out as tiny hot spots, while grease and finger smudges become highly visible surface swirls that tend to dim or fog the internal features.

Polarized Light. Polarized light microscopy is often thought of as a mineralogist's tool and has long been neglected by gemologists. Any gemological microscope with transmitted light capabilities can be easily converted, temporarily, to a polarizing microscope. Two polaroid plates are the only requirement. One polaroid, called the polarizer, is placed over the transmitted light port under the gem subject. The other polaroid, called the ana- 
lyzer, is placed over the gem subject in front of the microscope objective (as shown in figure 6). Normally, the analyzer is rotated and the polarizer remains fixed, but in this set-up both can be rotated. In routine examinations, unprotected plastic sheet polaroids with their fine scratches and slightly warped surfaces are adequate, but for photomicrography camera-type polaroid filters of good optical quality are needed.

In color and variety, the world of polarized light microscopy can be both startling and beautiful, especially if one is using this technique for the first time. Internal strain around included crystals, crystal-intergrowth induced strain, and twinning (as illustrated in figures 7, 8, and 9) all become visible under polarized light. Included crystals of very low relief, if doubly refractive, will stand out readily when polarized light is used and optic figures in gems can be located and photographed. If the polarizer is removed, the photographer can easily capture an inclusion in a strongly birefringent gem, such as peridot or zircon, by rotating the analyzer and clearing the otherwise strongly doubled image.

In polarized-light photomicrography, light levels are usually low and exposure times are correspondingly long; if vibrations are controlled, though, the photographic results can be quite spectacular.

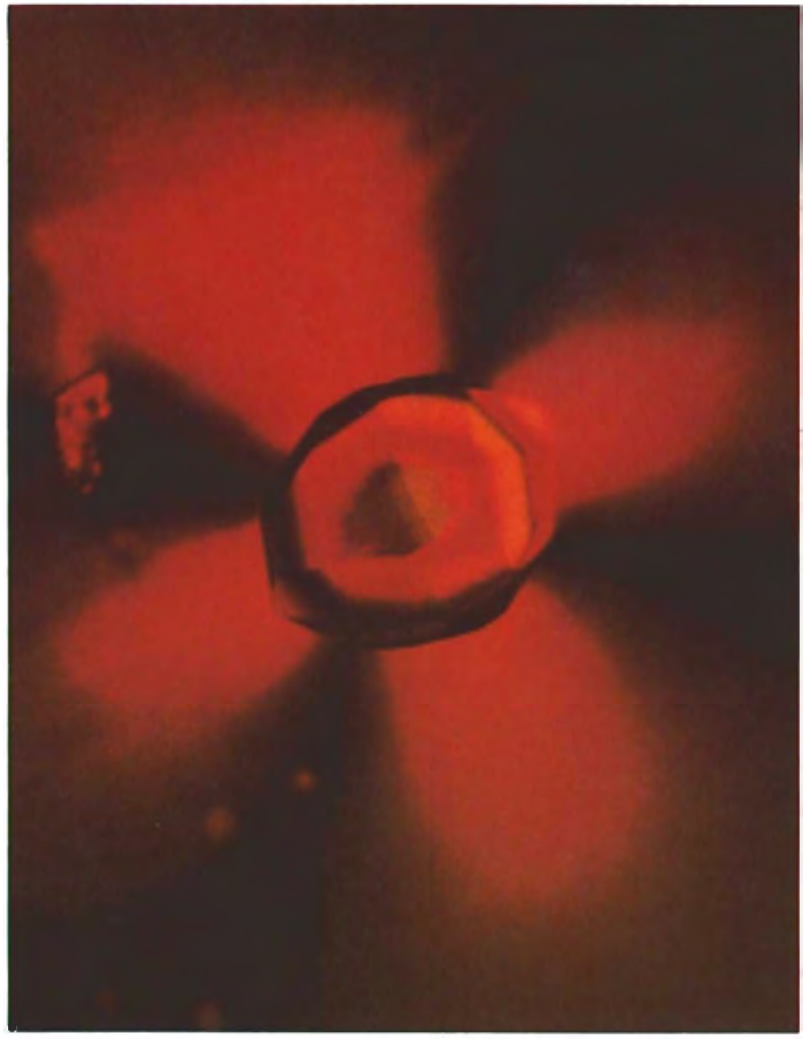

Figure 7. Under polarized light, a crystal of apatite included in an almandine garnet from Sri Lanka shows the strain it is causing in its host. Magnified $70 \times$
Figure 6. Polarized light microscopy requires the addition of only two polaroid plates, the polaroid polarizer and the polaroid analyzer, to convert a gemological microscope with transmitted light capabilities to a polarizing microscope.

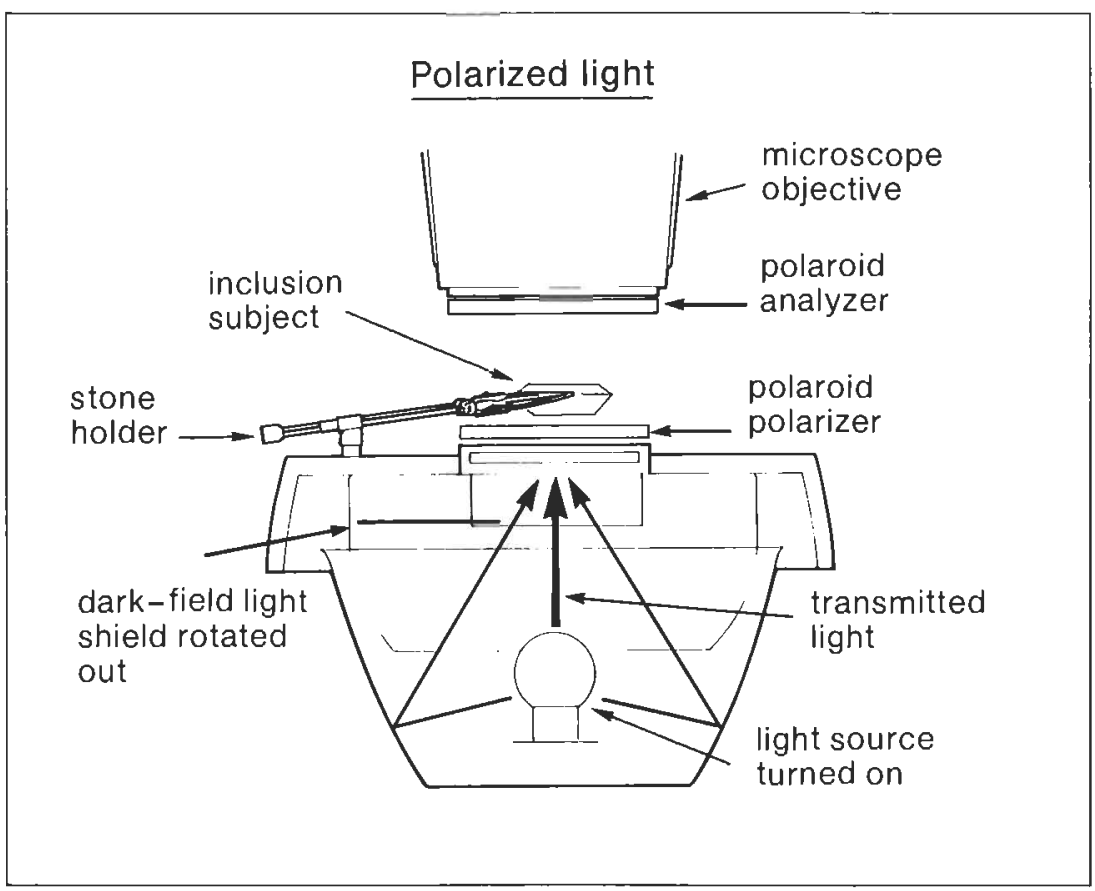




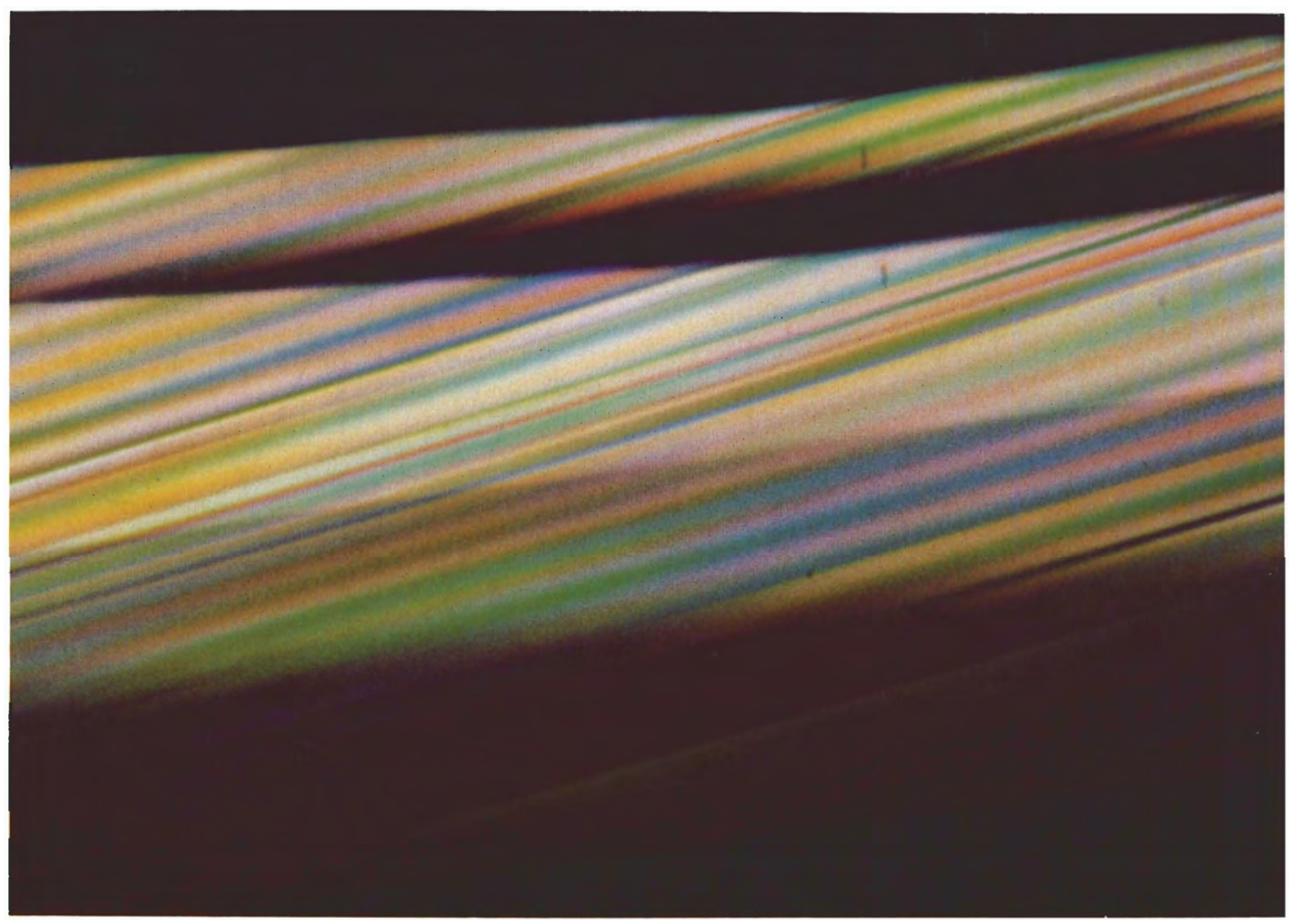

Figure 8. This brightly colored pattern is produced by the effect of polarized light on a twinned orthoclase feldspar from Itrongahy, Madagascar. Magnified $50 \times$.

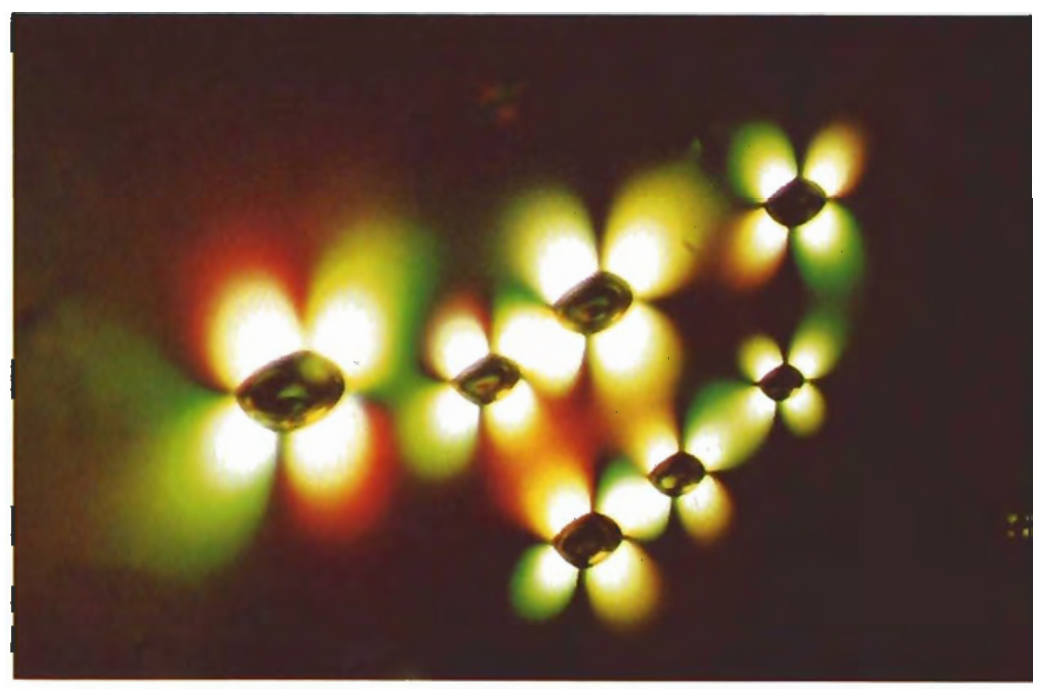

Figure 9. These seven gas bubbles in a piece of amber from the Dominican Republic reveal themselves to be strain centers under polarized light.

Magnified $30 \times$. 
Figure 10. To produce transmitted light, the dark-field light shield is removed and light is allowed to pass from directly below the gem, through the stone itself, upward into the microscope system.

\section{Transmitted light}
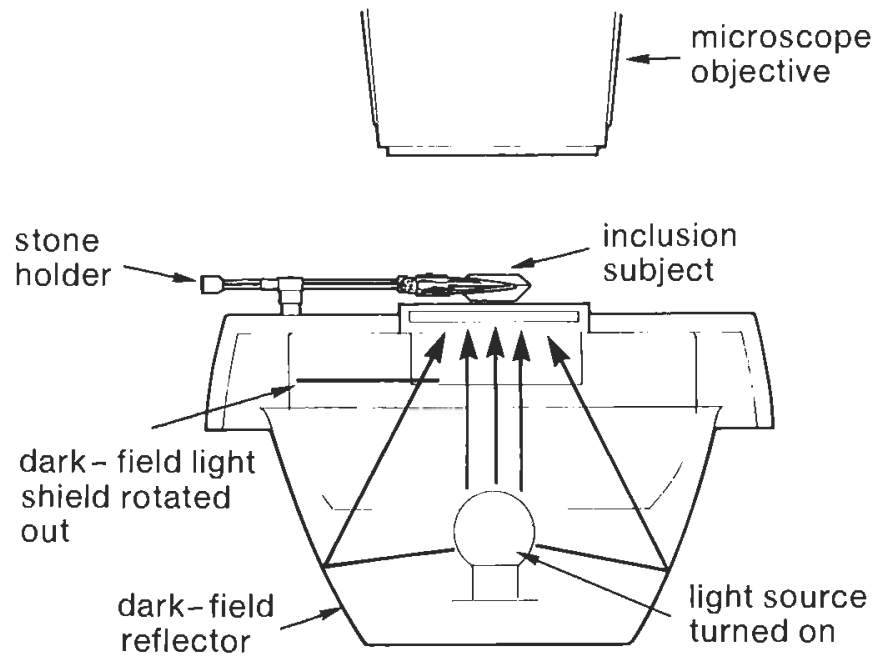

Transmitted Light. Transmitted light is produced by removing the dark-field light shield and allowing the passage of light from directly below the gem, through the gem itself, upward into the microscope system (see figure 10). A great deal of the detail normally seen with dark-field illumination is lost in transmitted light. Darkly colored or opaque included crystals and fine growth features are virtually washed out. Large fluid inclusions such as those shown in figure 11, however, are very easily examined in transmitted light. Details in these fluid chambers that were invisible under dark-field conditions stand out readily in a beam of transmitted light. Color zoning is also easily observed and photographed.

When transmitted light is used, exposure times are at their shortest. Small dust particles on the surface of the host gem are no problem, since the quantity of direct bright light washing around them tends to cancel their ability to interfere with light transmission.

Oblique Illumination. Between the $0^{\circ}$ angle of horizontal lighting and the $90^{\circ}$ angle of vertical illumination lies a range of angles that is known as the arc of oblique illumination (see figure 12).

Oblique illumination is seldom used in gemology except in the examination of opaque materials; when it is applied to transparent gems, however, the results can be both beautiful and fascinating. Behaving like thin films, fractures and ultra-thin liquid fingerprints /such as those shown in figures 13,14 , and 15) spring to life, dec-

Figure 11. This secondary healing plane of tiny negative crystal fluid inclusions in a spessartine garnet from Virginia is well detailed by transmitted light. Magnified $75 \times$.

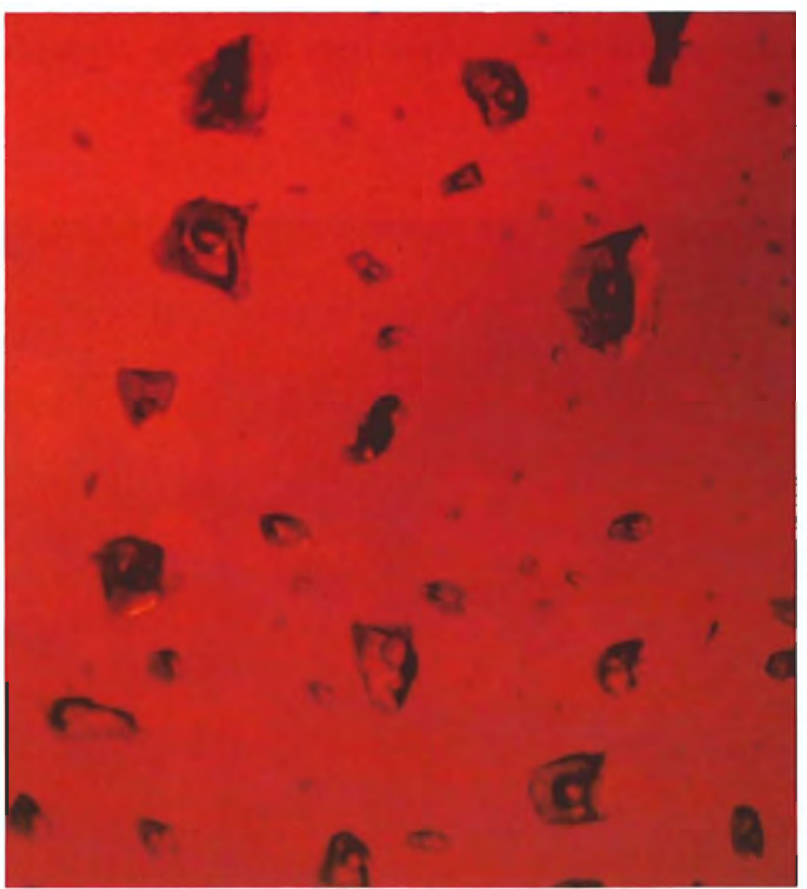




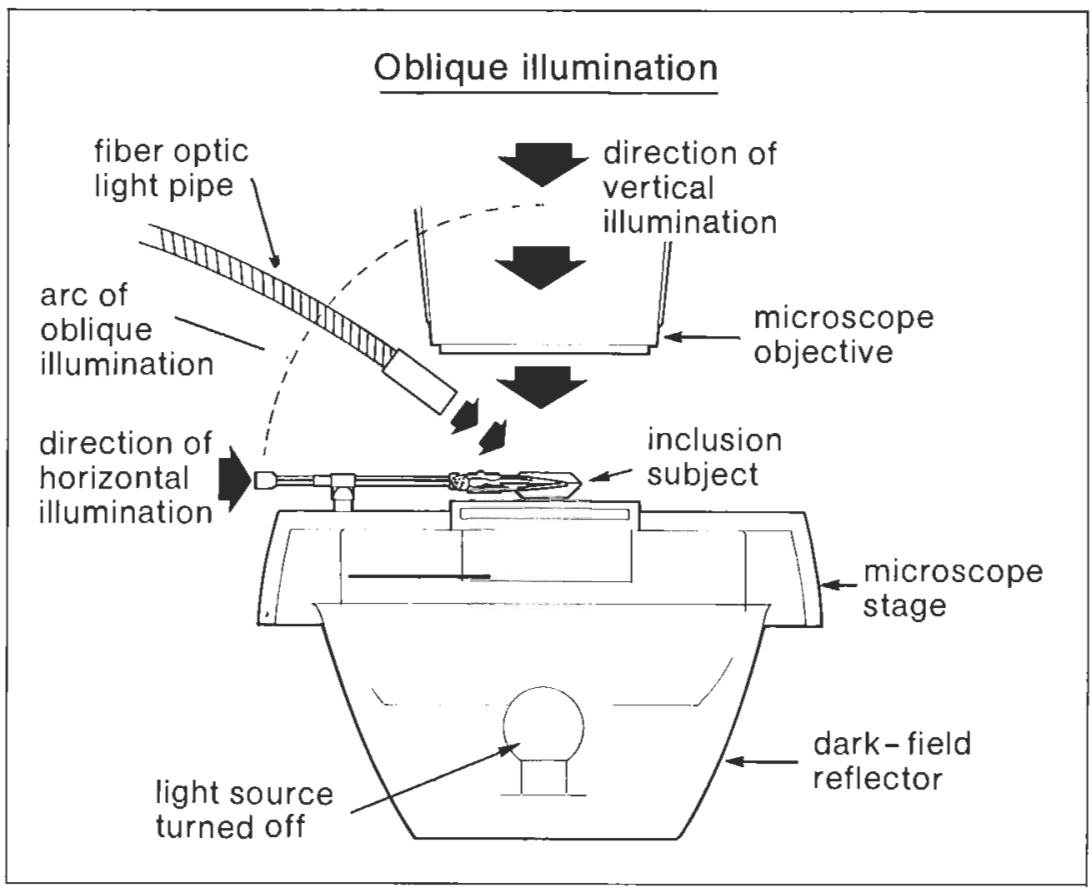

Figure 12. Oblique illumination involves the transmission of light from an outside source along the range of angles between the $0^{\circ}$ angle of horizontal lighting and the $90^{\circ}$ angle of vertical illumination.

Figure 13. This conchoidal fracture in a Brazilian beryl shows its every detail in vividly reflected colors. Oblique illumination, magnified $55 \times$.

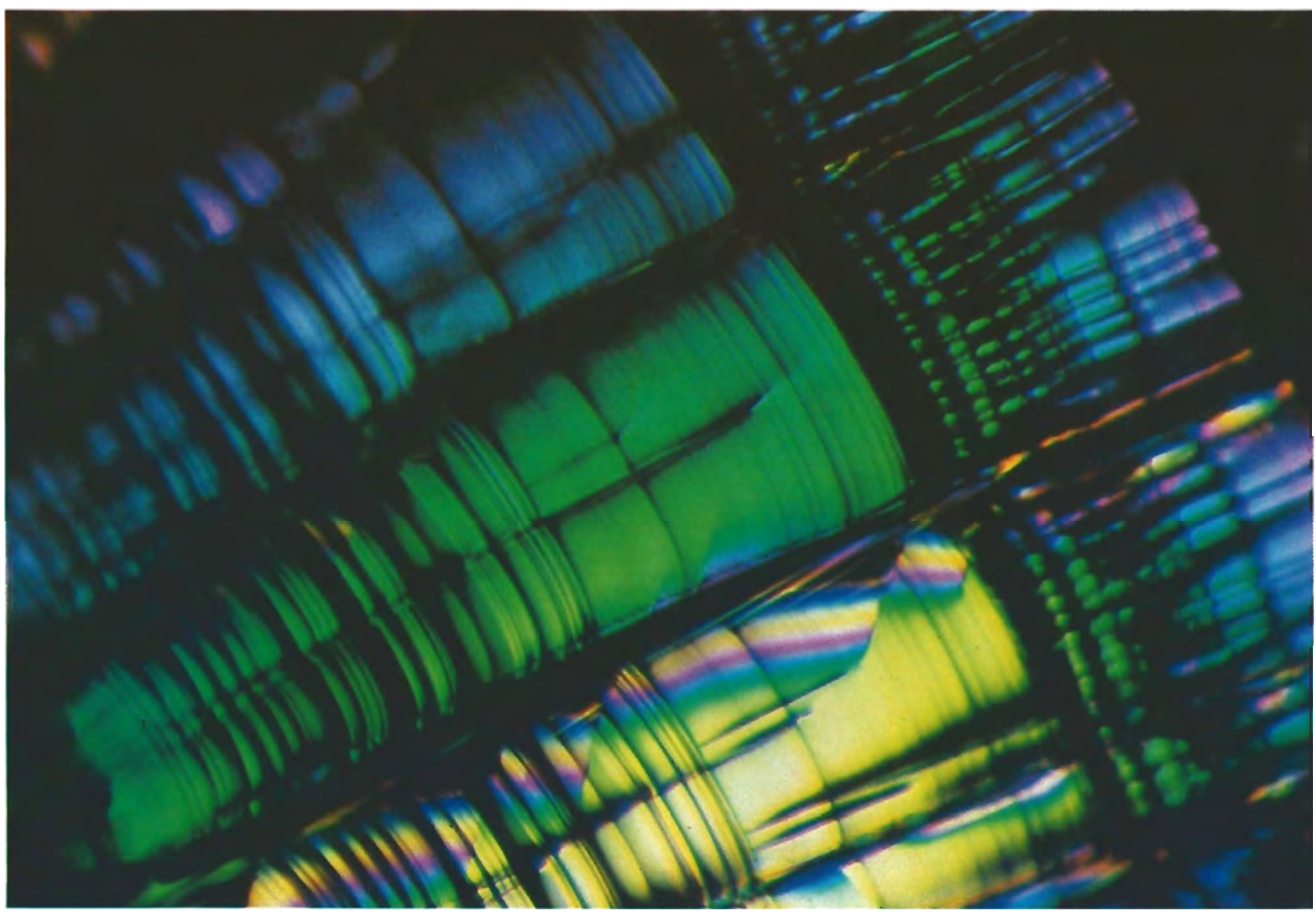




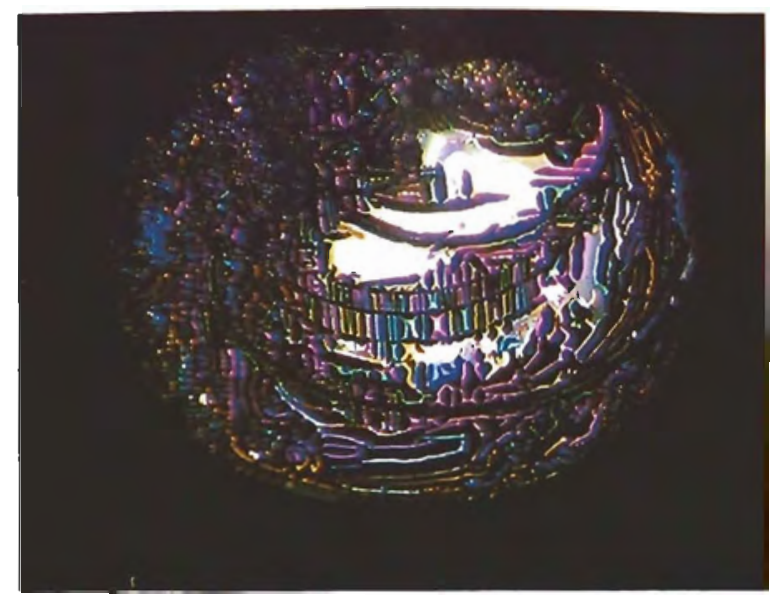

Figure 14. This partially healed pseudosecondary fracture was photographed in a high zircon from Sri Lanka. The color-reflecting veins are areas of separation, while the black represents areas that have healed. Oblique illumination, magnified $40 \times$.

orated by vibrant interference colors. Interfaces surrounding included crystals show details of growth on the crystals that otherwise elude observation. Reflecting facets return the oblique light rays to the observer's eye, seemingly magnifying their intensity and the richness of color.

A variety of lighting sources can be used for oblique illumination. One of the most efficient is a fiber optic illuminator, such as the one shown in figure 16.

Oblique illumination may also be used in combination with other methods of illumination,

Figure 16. A fiber optic illuminator, such as the one shown here, is an excellent source of oblique lighting. It can also be used to direct additional light where it is most needed, effectively reducing the exposure time in most cases.

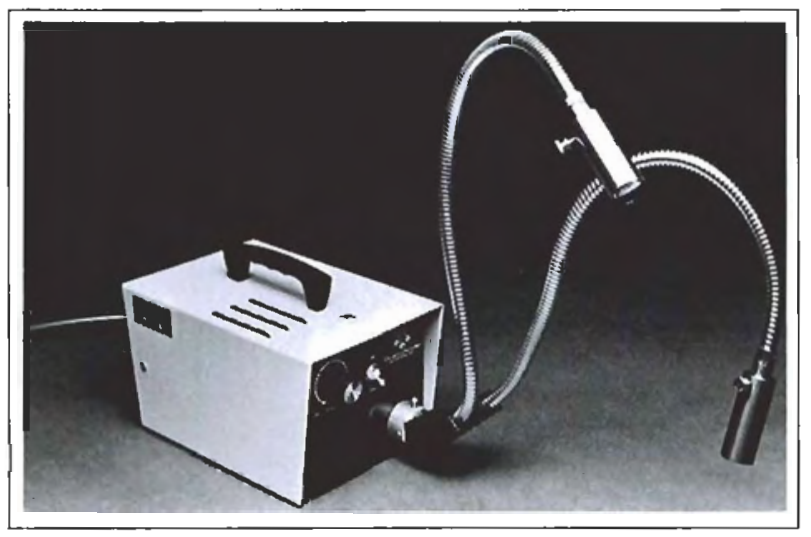

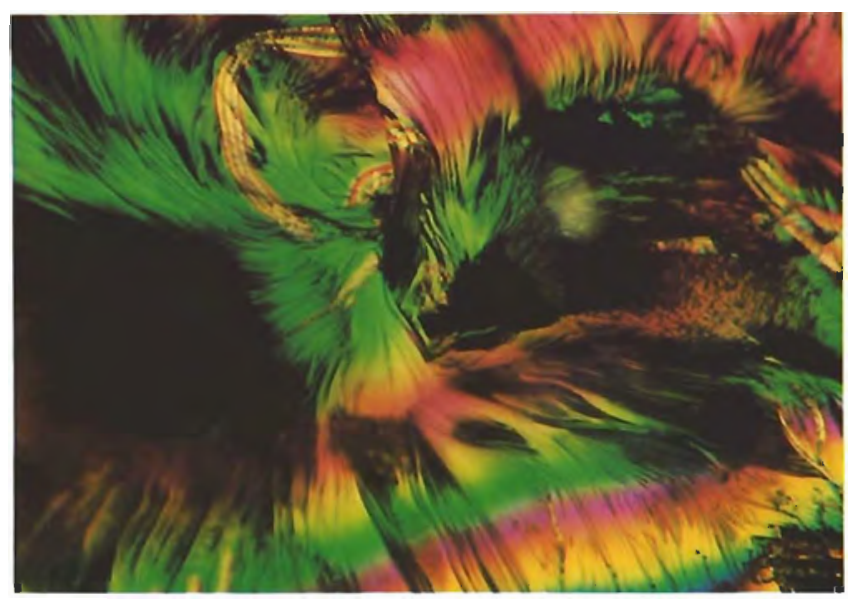

Figure 15. This cleavage in a fluorite from Colombia shows only small areas of nonseparation or healing (i.e., very little black). Oblique illumination, magnified $85 x$.

such as dark-field or polarized lighting, to add color highlights and additional light where needed, thus revealing more detail, adding desirable reflections, and reducing the exposure time required. Figures 17, 18, and 19 illustrate the results that may be obtained when oblique illumination is used with another lighting source.

Ultraviolet Illumination. The use of ultraviolet light in photomicrography and inclusion research

Figure 17. Under combined polarized and oblique illumination, these garnets in a diamond from Africa show the strain produced in the host gem as a direct result of their presence. Magnified $40 \times$.

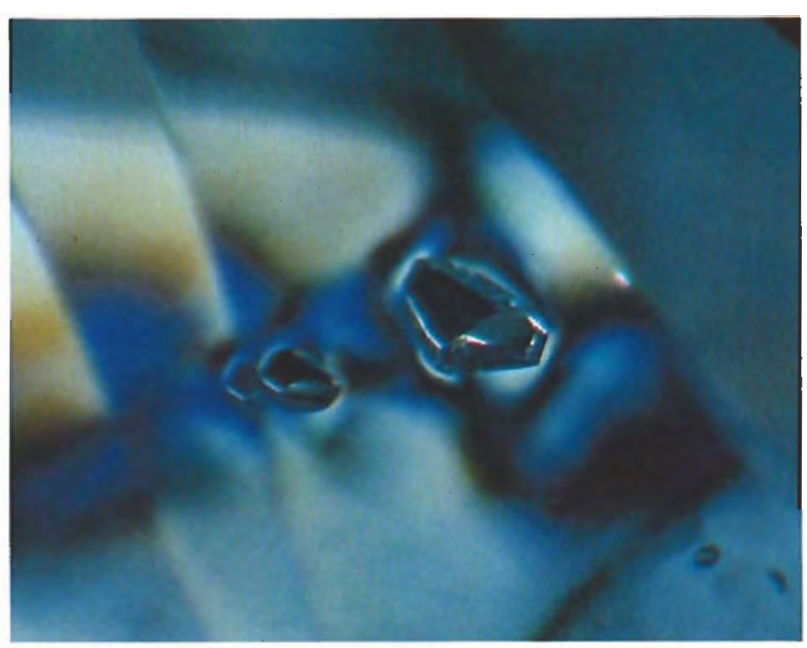


is somewhat limited. If the host gem material, such as quartz or flourite, is transparent to ultraviolet wavelengths, then certain included organic fluids (such as those in figure 20) and fluorescing solids will be seen to glow under the influence of the ultraviolet illumination. The low light levels of ultraviolet photomicrography often require excessively long exposure times, so slight vibrations in the equipment may become a problem.

\section{WHY NOT IMMERSION?}

Immersion techniques have their place in gemology; but not, at least in this writer's opinion, in photomicrography. A general rule of thumb is

Figure 18. As nucleating growth from their apatite centers, these stars of rutile in a red African garnet stand suspended above a plant of facet junctions. Dark-field and oblique illumination, magnified $30 \times$.

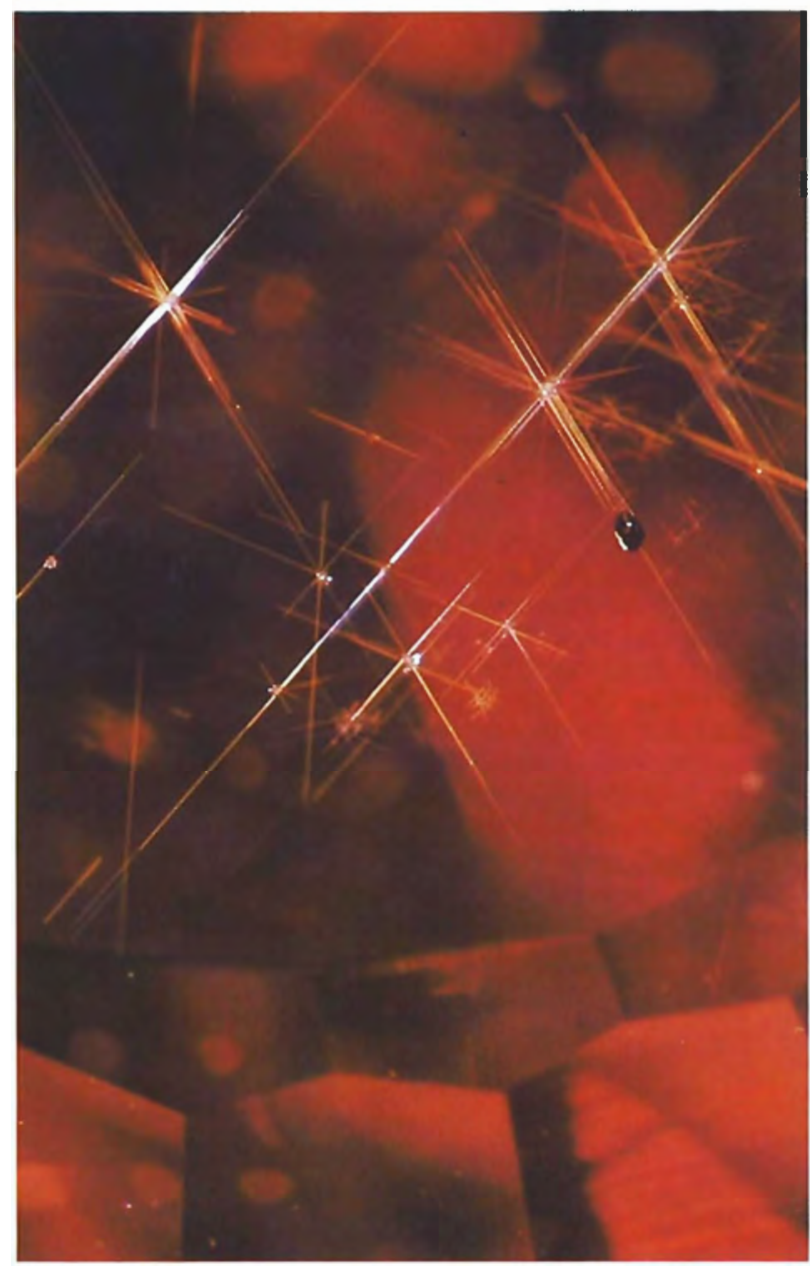

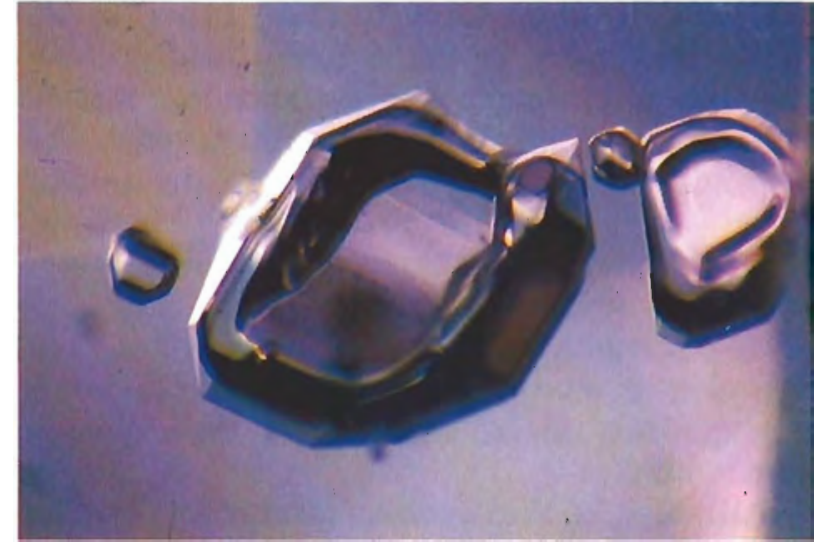

Figure 19. Under combined transmitted and oblique illumination, these negative crystals show not only their detailed form but also the amethystine coloration of their Brazilian quartz host. Magnified $70 \times$.

that the more lenses and other optically dense media that lie between the film plane and the subject, the lower the image quality will be. The common immersion liquids are dense, poisonous organic compounds that are typically colored. They generally are difficult to work with and sensitive to the bright lights that are needed for inclusion photography. Their colors tend to darken

Figure 20. Under long-wave ultraviolet illumination these spherical voids, filled with liquid petroleum - a solid tar-like substanceand a bubble of methane gas, cause the interior of their Illinois fluorite host to glow.

Magnified $35 \times$.

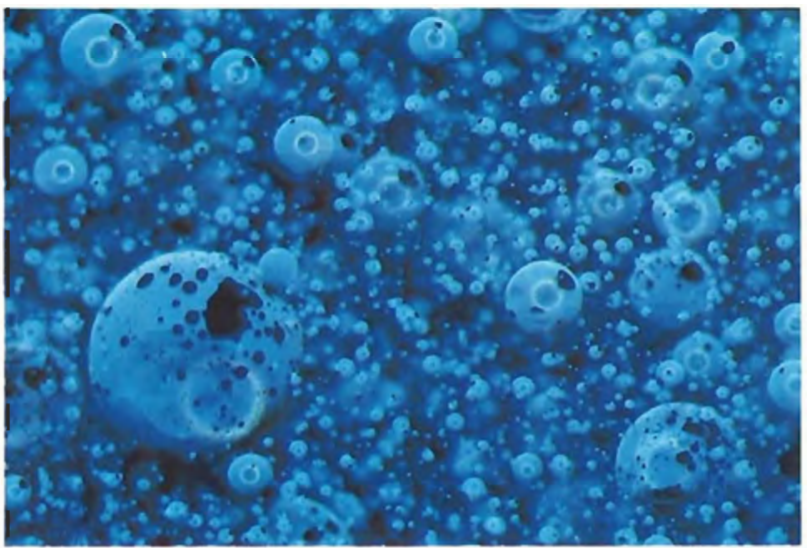


after only short exposure to these lights. In addition, they must be filtered continually to remove the microscopic dust particles that readily contaminate them. If they are not filtered, the suspended dirt will appear through the microscope as a milkiness composed of hundreds, or even thousands, of "floaters" in continuous motion, some in focus and some just out. The convection currents in these dense liquids are of ten seen as heat wave-like swirls that can distort a photographed image, especially if the exposure time is long.

Although, to the beginner, facet reflections are often very irritating and seemingly uncontrollable, with experience the photomicrographer will find that these reflections can become welcome sources of additional lighting and can add both color and desirable highlights to photomicrographs. It is important to work with the light by manipulating both the gem being photographed and the source $(s)$ of illumination. The use of immersion to control facet reflections, although somewhat tempting to the novice, only adds an additional thickness of optically dense material between the subject and the film, thus reducing the quality of the image.

\section{PHOTOGRAPHING SCRATCHED GEMS AND ROUGH CRYSTALS}

Occasionally a gem is encountered with unique internal patterns that beg to be photographed, but the surface of the stone is so badly scratched that obtaining a clear image is virtually impossible. In such situations, a modified immersion technique can work very effectively. This technique employs a small droplet of an index of refraction liquid, such as a Cargille liquid, with a refractive index very close to that of the gem being photographed. The droplet is placed on the scratched stone and, as it wets the gem's surface, all of the abrasions seem to disappear, effectively eliminat- ing the image obstructions and allowing a clear view of the gem's interior.

This technique has several advantages over total immersion. The liquid layer is very thin, so the effects of liquid color and density currents on image quality are negated. So little liquid is used that clean-up is very easy, and the strong odors that are so prevalent during total immersion are practically nonexistent. In addition, back reflecting facets can still be used to highlight the inclusion. This method is especially useful on soft, easily scratched gem materials such as amber.

This technique is also very helpful when studying the interiors of natural crystals through their rough crystal faces or waterworn surfaces. And it can be a tremendous aid in locating optic figures in anisotropic gemstones without having to resort to total immersion.

\section{CONCLUSION}

Inclusion photomicrography is a gemological skill that is well worth mastering. The knowledge necessary to obtain high-quality photomicrographs goes far beyond the mere mechanics of the marriage of microscope to camera, and in to the nature and very origins of the inclusions themselves.

Photomicrography adds yet another dimension to gemological microscopy and further aids the gemologist in recording and identifying stones and in appreciating the complex nature and striking beauty of inclusions in gems.

\section{REFERENCES}

Eastman Kodak Co. (1974) Photography through the Microscope. Kodak Publication No. P-2, Rochester, NY.

Gander R. (1969) Photomicrographic Techniques. Hafner Publishing Co., New York and London.

Lawson D.F. (1960) The Technique of Photomicrography. MacMillan Co., New York.

Loveland R.P. (1970) Photomicrography. A Comprehensive Treatise, Vols. I and 2. John Wiley \& Sons, New York.

Webster R. (1966) Photographic techniques used in gem testing. Journal of Gemmology, Vol. 1, pp. 13-17. 